\title{
Dislocation core structures in (0001) InGaN
}

S. L. Rhode ${ }^{1, *}$, M. K. Horton ${ }^{2, *}$, S. -L. Sahonta ${ }^{1}$, M. J. Kappers ${ }^{1}$, S. J. Haigh ${ }^{3,4}$, T. J. Pennycook ${ }^{4,}$

${ }^{5}$, C. McAleese ${ }^{1}$, C. J. Humphreys ${ }^{1}$, R. O. Dusane ${ }^{6}$, M. A. Moram ${ }^{1,2}$

1) Dept. Materials Science \& Metallurgy, University of Cambridge, Charles Babbage Road, Cambridge, CB3 OFS, UK.

2) Dept. Materials, Imperial College London, Exhibition Road, London, SW7 2AZ, UK.

3) School of Materials, University of Manchester, Manchester, M13 9PL, UK.

4) SuperSTEM, STFC Daresbury Laboratories, Warrington, WA4 4AD, UK.

5) Department of Materials, University of Oxford, Parks Road, Oxford, OX1 3PH, UK.

6) Dept. Metallurgical Engineering and Materials Science, Indian Institute of Technology Bombay, Mumbai, 400076, India.

\begin{abstract}
:
Threading dislocation core structures in $c$-plane $\mathrm{GaN}$ and $\operatorname{In}_{x} \mathrm{Ga}_{1-x} \mathrm{~N}(0.057 \leq x \leq 0.20)$ films were investigated by aberration-corrected scanning transmission electron microscopy. $a$-type dislocations are unaffected by alloying with indium and have a 5/7-atom ring core structure in both $\mathrm{GaN}$ and $\operatorname{In}_{x} \mathrm{Ga}_{1-x} \mathrm{~N}$. In contrast, the dissociation lengths of $(a+c)$-type dislocations are reduced and new 7/4/9-atom ring and 7/4/8/5-atom ring core structures were observed for the dissociated $(a+c)$-type dislocations in $\operatorname{In}_{x} \mathrm{Ga}_{1-x} \mathrm{~N}$, which is associated with the segregation of indium near $(a+c)$-type and $c$-type dislocation cores in $\operatorname{In}_{x} \mathrm{Ga}_{1-x} \mathrm{~N}$, consistent with predictions from atomistic Monte Carlo simulations.
\end{abstract}

Key words: Dislocations, InGaN, core structure, aberration-corrected STEM-HAADF, alloy segregation, STEM-EDXS

\section{Introduction}

$\mathrm{In}_{x} \mathrm{Ga}_{1-x} \mathrm{~N}$ semiconductor materials are widely used in light emitting diodes (LEDs) and laser diodes (LDs) [1], and have the potential to be used in solar cells [2] [3] as the direct band gap of

*S. L. Rhode and M. K. Horton have contributed equally to this work. 
$\mathrm{In}_{x} \mathrm{Ga}_{1-x} \mathrm{~N}$ can be engineered to absorb light over the entire visible spectrum, depending on the In content $(x)$ of the film [4]. $\operatorname{~n}_{x} \mathrm{Ga}_{1-x} \mathrm{~N}$ films with a thickness of around $100 \mathrm{~nm}$ have been applied for solar cell applications [2], whereas $\operatorname{In}_{x} \mathrm{Ga}_{1-x} \mathrm{~N}$ layers with a thickness between 2 and $5 \mathrm{~nm}$ are commonly deposited as multiple quantum wells (MQWs) in LEDs and LDs by metalorganic vapour-phase epitaxy (MOVPE).

GaN-based alloys usually contain a high density (as high as $5 \times 10^{9} \mathrm{~cm}^{-2}$ ) of threading dislocations (TDs). These one-dimensional defects originate near the interface between the group-III nitride material and the lattice-mismatched substrate [5], and thread up into the active regions $\left(\mathrm{In}_{x} \mathrm{Ga}_{1-x} \mathrm{~N}\right.$ MQWs) of optoelectronic devices. Three types of TDs are known to occur in group-III nitride films: with $a$-type (usually edge character), $(a+c)$-type (usually mixed character) and $c$-type Burgers vectors (usually screw character) [6]. Studies show that all $c$-type and $(a+c)$-type TDs in $\operatorname{In}_{x} \mathrm{Ga}_{1-x} \mathrm{~N}$ layers open up as inverted hexagonal pyramidal pits at the film surface [7] [8]. These TD endings appear as V-shaped voids in cross-sectional transmission electron microscopy (TEM) images of $\operatorname{In}_{\mathrm{x}} \mathrm{Ga}_{1-\mathrm{x}} \mathrm{N}$ films, and are thus known as $V$-defects. Previous studies show that V-defect formation is kinetically-driven and occurs independently of (although there have been predictions that V-defect formation may be assisted by) the presence of indium in the $\operatorname{In}_{x} \mathrm{Ga}_{1-x} \mathrm{~N}$ layers [9] [10].

Most TDs consist of a core region with broken or 'wrong' bonds (e.g. Ga-Ga, N-N), and/or a highly strained near-core region [11]. These deviations from ideal bonding introduce electronic states within the band gap. States in the band gap can trap carriers and act as carrier scattering centres and/or sites of non-radiative recombination [11] [12] [13] [14] [15]. These defects thus reduce the efficiencies and lifetimes of LEDs [4], and have been shown to increase leakage currents [16]. As the density and position of the electronic states depends on the nature of the bonding at and near TD cores, it is important to identify the core structures of TDs in the material in order to understand their influence on device properties.

For $a$-type dislocations in $\mathrm{GaN}$, all recent theoretical and experimental work has revealed that the most stable core structure is one that includes adjacent 5- and 7-atom rings in the (0001) plane [12] [13] [14] [17] [18] [19]. In addition, structures including 4- [20], 5/7- [21] and 8- [22] atom 
rings in the (0001) plane have been predicted as stable core structures for $a$-type dislocations in pure InN films, although these have not yet been observed. Experimental data for $(a+c)$-type dislocations in GaN films [23] show two core types, a double 5/6-atom ring structure and a dissociated core structure with two $(a+c) / 2$ partial dislocations joined by an extended planar fault containing alternating 8 -atom and 4-atom rings in the (0001) plane. This fault is also known as the Drum type prismatic stacking fault [24]. The core structures of the partial dislocations can vary, depending on the length of the extended planar fault [23]. However, although many experimental and theoretical studies exist on TD core structures in $\mathrm{GaN}$ and $\mathrm{InN}$ [12] [13] [14] [17] [18] [19] [20] [21] [22] [23] [24], no studies have been performed for the $\operatorname{In}_{x} \mathrm{Ga}_{1-x} \mathrm{~N}$ alloys used in devices. Such studies are important because local compositional fluctuations could modify TD core structures, affect the electronic states introduced into the band gap and/or influence carrier localisation during device operation. Therefore, this study reports both theoretical predictions and statistically reliable experimental data on the core structures of TDs in $\mathrm{GaN}$ and in $\operatorname{In}_{x} \mathrm{Ga}_{1-x} \mathrm{~N}$ alloys $(0.057 \leq x \leq 0.20)$ with In contents relevant to devices.

\section{Materials and methods}

All $\operatorname{In}_{x} \mathrm{Ga}_{1-x} \mathrm{~N}(0.057 \leq x \leq 0.20)$ samples were grown in a Thomas Swan $6 \times 2$ " close-coupled showerhead MOVPE reactor on $3.5 \mu \mathrm{m}$ thick low dislocation density (LDD) (with threading dislocation densities (TDDs) of $\left.\left.\sim(2.7 \pm 0.5) \times 10^{8} \mathrm{~cm}^{-2}\right)\right) \mathrm{GaN}$ epilayers grown on sapphire (0001) substrates with a miscut of $0.25 \pm 10^{\circ}$ towards the $\langle 11 \overline{2} 0\rangle$ direction. Trimethylgallium (TMG), trimethylindium (TMI) and ammonia were used as precursors for Ga, In and N, respectively, using nitrogen $\left(\mathrm{N}_{2}\right)$ as the carrier gas. The active layer of an LED structure consists of thin strained $\operatorname{In}_{x} \mathrm{Ga}_{1-x} \mathrm{~N}$ MQW layers, where $\mathrm{GaN}$ barriers are always grown between the alternating $\operatorname{In}_{x} \mathrm{Ga}_{1-x} \mathrm{~N}$ QWs. This growth is repeated for the number of QWs required, always finishing with a $\mathrm{GaN}$ barrier layer on top [25]. As the presence of these alternating GaN barrier layers may influence the structure of the TD core in the $\operatorname{In}_{x} \mathrm{Ga}_{1-x} \mathrm{~N}$ layers, the effect of In-alloying on the structure and composition of TD core and near core regions in $\mathrm{GaN}$ is best investigated by studying TD core structures in strained [26] $\operatorname{In}_{x} \mathrm{Ga}_{1-x} \mathrm{~N}$ epilayer samples. Two epilayer samples, one with $x=0.057 \pm 0.01$ (Sample A) and the other with $x=0.20 \pm 0.01$ (Sample B) (as measured previously by wavelength-dispersive X-ray studies [27]) were grown at temperatures

of $750{ }^{\circ} \mathrm{C}$ and $710{ }^{\circ} \mathrm{C}$. Previous XRD studies on these $160 \mathrm{~nm}$ thick samples predicted negligible 
strain-relaxation for Sample A and a strain relaxation value of $8 \pm 1 \%$ for Sample B [26]. Crosssectional high-resolution transmission electron microscopy studies for both samples also showed the absence of misfit dislocations at the $\operatorname{In}_{x} \mathrm{Ga}_{1-x} \mathrm{~N} / \mathrm{GaN}$ interface, further confirming that these films are strained [26]. The indium content of these films was varied by keeping the TMI flux constant, and by reducing the reactor susceptor temperature to incorporate more indium into the epilayer. Additionally, a $110 \mathrm{~nm} \mathrm{GaN}$ epilayer (Sample C) was also studied to investigate the effect of compressive interfacial strain introduced by indium atoms in the $\operatorname{In}_{x} \mathrm{Ga}_{1-x} \mathrm{~N}$ layers. This sample was grown with all reactor conditions similar to that of Sample A, except that no TMI was introduced during the growth of the low-temperature GaN epilayer. For comparison, a GaN film (Sample D) grown at $1010{ }^{\circ} \mathrm{C}$ on sapphire with no subsequent deposition was also studied during the course of this work. Further details of GaN epilayer growth on sapphire are described elsewhere [24] [28].

Plan-view and cross-sectional TEM specimens were prepared for all films by mechanical polishing, followed by back-thinning with $\mathrm{Ar}^{+}$ions at $5 \mathrm{kV}$. The final step involved ion milling at $2 \mathrm{keV}$ to minimize specimen damage. Weak-beam dark-field (WBDF) images for all samples were acquired at $400 \mathrm{keV}$ on a JEOL 4000 microscope. High-angle annular dark field (HAADF) imaging in the scanning transmission electron microscopy (STEM) mode was performed using an aberration-corrected $\operatorname{Titan}^{3} 80-300$ at $300 \mathrm{keV}$ where at least fifty dislocations were observed for each sample for statistical validity. Aberration-corrected high-resolution (HR) STEMHAADF images of TD cores were also acquired at $80 \mathrm{keV}$ on a Nion UltrastemTM 100 microscope to investigate whether the $300 \mathrm{keV}$ beam on the $\operatorname{Titan}^{3} 80-300$ introduces any beam damage to the TDs. All geometric aberrations in the electron beam probe were corrected up to the third order by recording Zemlin tableau diffractograms. All experimental images were processed using an average background subtraction filter with a cycle of 20 and 5 steps. Energy dispersive X-ray spectroscopy (EDXS) studies were also performed on a probe side aberrationcorrected Titan G2 80-200kV ChemiSTEM electron microscope fitted with the Super-X EDXS detector system to study ten $(a+c)$-type and two $c$-type dislocations (as only 1\% of such type are present). All EDXS spectral images were acquired with a probe current of $1 \mathrm{nA}$ and a convergence angle of $21 \mathrm{mrad}$ to maximize the measurement of the EDXS signal. Moreover, all maps were acquired for a total time of $1200 \mathrm{~s}$ with dwell times of $25 \mu \mathrm{s} /$ pixel where a spectrum 
was acquired at every pixel. All data were analyzed using the Bruker Esprit software. Geometric phase analysis (GPA) was also carried out to measure strain from the atomic-resolution STEMHAADF images. In-plane strain $\left(\varepsilon_{x x}\right)$ maps around dislocations were calculated by taking the unstrained region of the image as a reference, similar to the approach used by Mouti et al. [29].

Theoretical predictions were also made using a Metropolis Monte Carlo method, with the positions of $\mathrm{Ga}$ and In atoms swapped at random within a cylindrical region of $4.46 \mathrm{~nm}$ around a dislocation core, and with differences in energies between trial configurations calculated by geometry optimization using the LAMMPS molecular dynamics code (MD) [30] and StillingerWeber potentials for InN [20] and GaN [31] [32] [33] [34]. Simulation cells were $64 \times 64 \times 4$ unit cells in size ( $a=3.19 \AA, c=5.19 \AA$, which match those optimized by the Stillinger-Weber potential and also the corresponding directions of the supercell, [ $\left[\begin{array}{lll}1 & 0 & 0\end{array}\right]$ by $\left[\begin{array}{lll}0 & 1 & 0\end{array}\right]$ by $\left.\left[\begin{array}{lll}0 & 0 & 1\end{array}\right]\right)$ and contained a dislocation dipole, with cell dimensions strained to match a GaN lattice. The Monte Carlo simulations were continued until the total potential energy of the cell converged, and from this equilibrium core configurations were extracted. Further details of this model are available in our previous work [33].

\section{Results and discussion}

WBDF images of Samples A-D are shown in Figure 1. TDs are clearly seen to terminate as Vdefects at the surface of both Sample A and Sample B (as shown in Figure 1 (a, b)). A previous report showed that the $\mathrm{V}$-defect density (calculated from the pit density of the AFM images acquired for these $\operatorname{In}_{x} \mathrm{Ga}_{1-x} \mathrm{~N}$ samples [26]) remained constant even when the In content was increased from $x=0.057$ in Sample A to $x=0.20$ in Sample B. The V-defect density remained constant at the same density as the $c$-type and $(a+c)$-type dislocation density of the GaN template on which the $\operatorname{In}_{x} \mathrm{Ga}_{1-x} \mathrm{~N}$ samples were grown, although the widths and depths of these defects increased with increasing In content of the sample (as shown in Figures 1 (a, b)). Basic characterization data on V-defects in these $\operatorname{In}_{\mathrm{x}} \mathrm{Ga}_{1-\mathrm{x}} \mathrm{N}$ epilayer samples has been reported in a previous publication [26]. 
The TD core structures for all four samples were studied by HRSTEM-HAADF imaging on the $\operatorname{Titan}^{3}$ 80-300 microscope. The $a$-type TDs could be distinguished clearly from the $(a+c)$-type dislocations as $a$-type dislocations do not terminate as V-pits at the surface [7] [8] of Samples A and B, and none of the STEM data acquired for $a$-type dislocations in any of the samples showed contrast due to the Eshelby Twist of the lattice which is associated with dislocations having a $c$ component of the Burgers vector [35]. However, these samples contained a very low proportion of $c$-type dislocations, meaning that statistically reliable data could not be obtained for this type of dislocation.

Our statistically valid HRSTEM-HAADF study shows that the $a$-type dislocation cores in all samples formed 5/7-atom ring structures, independent of growth conditions or In content. The effect of growth temperature on the dislocation core structures was investigated by comparing Sample C (GaN grown at $750^{\circ} \mathrm{C}$ ) and Sample D (GaN grown at $\left.1010^{\circ} \mathrm{C}\right)$. In both samples, only 5/7-atom ring core structures were observed for $a$-type dislocations, whereas both the undissociated double 5/6-atom ring cores and the dissociated cores were observed for $(a+c)$-type dislocations (as summarized in Table 1). The only observed difference between Samples C and $\mathrm{D}$ was that the average dissociation length for the dissociated $(a+c)$-type dislocations reduced slightly for Sample C, which may be related to the differences in the in-plane strain in the films due to growth at different temperatures. This indicates that even large changes in growth temperature do not affect dislocation core structures in $\mathrm{GaN}$, and therefore smaller changes in growth temperature from $750{ }^{\circ} \mathrm{C}$ to $710^{\circ} \mathrm{C}$ are unlikely to affect dislocation core structures in the $\operatorname{In}_{x} \mathrm{Ga}_{1-x} \mathrm{~N}$ layers studied in this paper.

The effect of introducing indium during growth was investigated by comparing Sample A $\left(\mathrm{In}_{0.057} \mathrm{Ga}_{0.943} \mathrm{~N}\right.$ grown at $\left.750{ }^{\circ} \mathrm{C}\right)$ with Sample $\mathrm{C}\left(\mathrm{GaN}\right.$ grown at $\left.750{ }^{\circ} \mathrm{C}\right)$. As indicated in Table 1 , no change occurs for the $a$-type dislocation cores but there is a tendency towards reduced dissociation lengths for the dissociated $(a+c)$-type dislocations in both InGaN films. This is because in addition to the dissociated 7/4/8/4/9-atom rings which have previously been observed for $\mathrm{GaN}$ samples [24], 7/4/9-atom ring and 7/4/8/5-atom ring dissociated $(a+c)$-type dislocation core structures are also observed in the $\operatorname{In}_{x} \mathrm{Ga}_{1-x} \mathrm{~N}$ layers (which have not previously been 
reported). Figure 2 shows micrographs and the corresponding simulated core structures for each type of TD found in the $\operatorname{In}_{x} \mathrm{Ga}_{1-x} \mathrm{~N}(x \leq 0.20)$ layers.

The appearance of the 7/4/9-atom ring and 7/4/8/5-atom ring $(a+c)$-type dislocation core structures (i.e. the shortening of the $(a+c)$-dislocation dissociation lengths) can be attributed to the segregation of In atoms at or near dislocation cores in $\operatorname{In}_{x} \mathrm{Ga}_{1-x} \mathrm{~N}$. As In atoms are relatively larger than Ga atoms [36] [37], they are expected to preferably occupy sites in the region of tensile strain next to the cores of $a$-type or $(a+c)$-type dislocations [37], thereby decreasing the elastic strain energy per unit length of the dislocation, thus inhibiting the dislocations from dissociating into faults with greater lengths. Previous molecular dynamics simulations also indicate that In is expected to bind directly to cores with $c$-components, decreasing their core energies [38] [39]. Previous cathodoluminescence measurements [40] [41] have indirectly suggested that In preferentially segregates to dislocation cores in $\operatorname{In}_{x} \mathrm{Ga}_{1-x} \mathrm{~N}$, however, direct evidence of In segregation to dislocation cores has not been reported in the literature [42] [43]. Thus, simultaneous bright-field (BF) images and STEM-EDXS maps of TD terminations as Vdefects were obtained for both the $\operatorname{In}_{x} \mathrm{Ga}_{1-x} \mathrm{~N}$ samples to observe any In segregation near the TD core.

Our STEM-EDXS maps show that In segregates to near-dislocation-core locations for both Samples A and B (as shown in Figure 3 (c, d)). The HRSTEM-HAADF images for Sample A and Sample B show been shown to possess the 7/4/8/5-atom and the double 5/6-atom TD core structures respectively (as shown in Figure $3(\mathrm{e}, \mathrm{f})$ ). As only TDs with $c$-components open up as V-pits [7] [8], and only $(a+c)$-type TDs have the 7/4/8/5-atom and the double 5/6-atom TD core structures (as shown in Figures $2(\mathrm{a}, \mathrm{c})$ ), the TDs observed in Figure 3 are therefore of the $(a+c)$ type. Hence, our STEM-EDXS maps confirm that In segregates to $(a+c)$-type TD cores in $\mathrm{In}_{\mathrm{x}} \mathrm{Ga}_{1-\mathrm{x}} \mathrm{N}$. As a larger aperture was used to increase the STEM-EDXS signal, the spatial resolution of the simultaneously acquired STEM-HAADF images was considerably compromised. Hence, the atomic columns at TD core locations in Figure 3 (e, f) have been labelled to aid the eye. The corresponding MD simulations of core structures observed in Figure $3(\mathrm{e}, \mathrm{f})$ are shown in Figures $3(\mathrm{~g}, \mathrm{~h})$. 
Semi-quantitative absorption corrected Cliff-Lorimer [44] analysis was also applied to the region around the TD core (marked in Figure 3 (c)) to quantify the amount of In segregation near the $(a+c)$-type TD. The calculations predicted an In composition of $6 \pm 1.7 \mathrm{wt} \%, 10.5 \pm 1.7 \mathrm{wt} \%$ and $3 \pm 1.7 \mathrm{wt} \%$ in the matrix, at the TD core location and between the V-pit facet vertices (region marked in Figure 3 (c)), respectively. As the In content in the matrix, measured by the CliffLorimer analysis is within the error limit of the In content measured by Rutherford backscattering studies for Sample A [27], these calculations are highly reliable, and confirm the presence of an In-rich region near the TD core, and an In-poor region between the V-defect facet vertices.

Monte Carlo simulations were also performed for $(a+c)$-type TDs in $\operatorname{In}_{\mathrm{x}} \mathrm{Ga}_{1-\mathrm{x}} \mathrm{N}$ with In contents $x$ $=0.0625$ and $x=0.1875$ to provide a comparison for the STEM-EDXS results obtained for Samples A and B in Figures 3 (c, d). Images of these simulations are shown in Figure 4 (a, b), which indicate preferential segregation of In to the $(a+c)$-type TDs, with In content in the core region predicted to be approximately double that of the bulk, consistent with the STEM-EDXS results.

The high-resolution STEM-EDXS data of an $(a+c)$-type TD in Sample A (as shown in Figure 5 (a)) also show segregation of In at the apex of the V-pit and at all vertices between the V-defect facets ((Figure $3(\mathrm{c}, \mathrm{d}))$. This is in good agreement with previous theoretical studies which predicted local strain relaxation at the apex of the V-pit [45] and preferential segregation of In to the vertices of the V-defect [46]. This is because the In-N bond is longer and weaker than the Ga-N bond [46] [47], and the In atoms prefer to segregate to the vertices between V-defect facets as these facets offer sites of reduced $\mathrm{N}$ coordination.

Moreover, a particularly high degree of In segregation was observed at one of the vertices for Sample A, as shown in Figures 3 (c) and 5 (a). The STEM-HAADF image presented in Figure 5 (b) also shows a higher STEM-HAADF contrast at the vertex labelled ' 3 ' which could be attributed to higher strain or to segregation of elements with higher atomic number $Z$. 
The STEM-EDXS elemental map of In (Figure 5 (a)) shows preferential In segregation at the same vertex which shows a higher STEM-HAADF contrast in the STEM-HAADF image (Figure 5 (b)). GPA was performed on the boxed region in the STEM-HAADF image in Figure 5 (b), and the colour scale in Figure 5 (c) shows an in-plane $x$-x strain-map $\left(\varepsilon_{x x}\right)$ of the dislocation (where the tensile (+) and compressive (-) regions of strain near the dislocation are marked). The presence of the $c$-component of the $(a+c)$-type dislocation and In segregation to the core results in slight deviations from the perfect compressive-tensile lobe contrast observed in GPA images calculated for $a$-type dislocations [29]. Comparison of Figures 5 (a), (b) and (c) confirm that In segregation and higher STEM-HAADF contrast are observed in the tensile strain region of the TD.

Furthermore, the STEM-HAADF image of a TD in Sample C (which does not contain any In) also shows a higher contrast near the TD core (as seen in Figure 6 (a)). The strain-field map $\left(\varepsilon_{\mathrm{xx}}\right)$ of the TD which shows the tensile and compressive regions of the $a$-component of the TD was superimposed on the HRSTEM-HAADF image of the same TD showing double 5/6-atom core in Figure 6 (b) (note that the double 5/6-atom ring core cannot be distinguished clearly from the 8atom ring core in these images). The presence of the double 5/6-atom [24] TD core suggests that the nature of the TD is $(a+c)$-type. Thus, the presence of higher STEM-HAADF contrast in the tensile strained region of an $(a+c)$-type TD in Sample C (undoped GaN grown at LT) suggests that long-range tensile strain caused by TDs (and not In segregation at TD cores) causes the higher HAADF contrast at one of the V-defect facet vertices.

Our results confirm that In preferentially segregates to regions of tensile strain near $(a+c)$-type dislocations in $\operatorname{In}_{x} \mathrm{Ga}_{1-x} \mathrm{~N}(x=0.057)$ epilayer samples. These results are consistent with previous STEM-HAADF studies on $(a+c)$-type dislocations in lattice-matched $\operatorname{In}_{x} \mathrm{Al}_{1-x} \mathrm{~N}(x=0.18$ to 0.20$)$ grown on $\mathrm{GaN}$ [29] which reported In segregation at the tensile region around an $(a+c)$-type dislocation.

Of course, $(a+c)$-type dislocations in $\operatorname{In}_{x} \mathrm{Ga}_{1-x} \mathrm{~N}$ are also terminated by a V-pit during growth, which may influence the extent of In segregation. However, modelling the influence of the V-pit 
is highly challenging and beyond the scope of equilibrium Monte Carlo simulations: it requires modelling growth conditions, including kinetic effects, adatom diffusion, and the influence of the complex gaseous atmosphere in the growth chamber. However, the observed In segregation is highly directional and consistent with our simulations, without showing significant deviations from theoretical predictions as would be expected if the V-pit contributed significantly to the In distribution.

In segregation was also observed near $c$-type dislocation cores in $\operatorname{In}_{\mathrm{x}} \mathrm{Ga}_{1-\mathrm{x}} \mathrm{N}$, where an example of In segregation at a $c$-type TD in Sample A is shown in Figure 7 (a). The screw character of the TD was identified from the high-resolution STEM-HAADF image of the core and near core region which shows the absence of an extra-half plane (an indicator of the $a$-component of a TD). Moreover, Eshelby Twist, which is an apparent rotation of the lattice caused by the relaxation of stresses at the free surface caused by the introduction of a $c$-type TD into the material [35] was observed. The corresponding Monte Carlo simulation for a $c$-type TD core in $\mathrm{In}_{0.057} \mathrm{Ga}_{0.943} \mathrm{~N}$ also shows preferential In segregation to the core region (as shown in Figure 7 (b)), suggesting that In segregates to both $c$ - and $(a+c)$-type TDs in $\operatorname{In}_{x} \mathrm{Ga}_{1-x} \mathrm{~N}$. The typically low prevalence of $c$-type dislocations in III nitride samples meant that no $c$-type dislocations were observed for $\mathrm{In}_{0.20} \mathrm{Ga}_{0.80} \mathrm{~N}$ (Sample B).

All STEM-EDXS experiments were carried out at $300 \mathrm{keV}$ to increase the signal-to-noise ratios of the STEM-EDXS signals measured. Although previous studies have observed In clustering caused by beam damage in $\operatorname{In}_{\mathrm{x}} \mathrm{Ga}_{1-\mathrm{x}} \mathrm{N}$ samples in the past [48], the In clusters were observed throughout the TEM foil under investigation, and not just at the tensile region of the core as is observed by our study.

In summary, our results confirm that In segregates to $(a+c)$-type and $c$-type dislocation cores in $\mathrm{In}_{\mathrm{x}} \mathrm{Ga}_{1-\mathrm{x}} \mathrm{N}(x=0.057$ to 0.20$)$. This experimentally-observed composition variation near the $(a+c)$-type and $c$-type dislocation cores could affect the electronic properties of devices containing $\operatorname{In}_{\mathrm{x}} \mathrm{Ga}_{1-\mathrm{x}} \mathrm{N}$-based active regions. This segregation is also associated with the appearance of new $(a+c)$-type dislocation cores in $\operatorname{In}_{\mathrm{x}} \mathrm{Ga}_{1-\mathrm{x}} \mathrm{N}$, compared to those found in $\mathrm{GaN}$. As the double 5/6-atom core [31] and the 7- and the 9-atom rings at both ends of a dissociated 
7/4/8/4/9-atom core [34] have all been suggested to introduce deep states in the GaN band gap, the new core structures observed for $(a+c)$-type TDs in $\operatorname{In}_{\mathrm{x}} \mathrm{Ga}_{1-\mathrm{x}} \mathrm{N}$ films are likely to introduce additional states in the $\operatorname{In}_{x} \mathrm{Ga}_{1-\mathrm{x}} \mathrm{N}$ band gap. Therefore, the electronic properties of dislocations in $\mathrm{In}_{\mathrm{x}} \mathrm{Ga}_{1-\mathrm{x}} \mathrm{N}$ are likely to be different from those in $\mathrm{GaN}$. At any given dislocation, there will be multiple possible spatial distributions of In on the metal sites at and near the dislocation core. The electronic structure must therefore be calculated for a statistically appropriate set of multiple dislocations, in which each has the same core structure but with In atoms located on different sites. This computationally intensive work will be addressed in a future paper.

\section{Acknowledgements}

This work was funded in part by the Cambridge Commonwealth Trust, St. John's College and the EPSRC (grant number EP/I012591/1). MAM acknowledges support from the Royal Society through a University Research Fellowship. Additional support was provided by the EPSRC (Supplementary data for EPSRC [49] is available) through the UK National Facility for Aberration-Corrected STEM (SuperSTEM). The Titan $80-200 \mathrm{kV}$ ChemiSTEM ${ }^{\mathrm{TM}}$ was funded through HM Government (UK) and is associated with the capabilities of the University of Manchester Nuclear Manufacturing (NUMAN) capabilities. SJH acknowledges funding from the Defence Threat Reduction Agency (DTRA) USA (grant number HDTRA1-12-1-0013). The authors also acknowledge C. M. McGilvery and A. Kovacs for helpful discussions.

\section{References}

[1] S. Nakamura, Jpn. J. Appl. Phys., 30, L1705, 1991.

[2] J. Wu, W. Walukiewicz, K. M. Yu, W. Shan, J. W. Ager III, E. E. Haller, H. Lu, W. J. Schaff, W. K. Metzger, S. Kurtz, J. Appl. Phys., 94, 6477, 2003.

[3] Y. Zhang, M. J. Kappers, D. Zhu, F. Oehler, F. Gao, C. J. Humphreys, Solar Energy Mat. and Solar Cells, 117, 279, 2013.

[4] R. Singh, D. Doppalapudi, T. Moustakas, L. Romano, Appl. Phys. Lett., 70, 1089, 1997.

[5] M. A. Moram, C. S. Ghedia, D. V. S. Rao, J. S. Barnard, Y. Zhang, M. J. Kappers, and C. J. Humphreys, J. Appl. Phys., 106, 073513, 2009.

[6] F. A. Ponce, D. Cherns, W. T. Young, J. W. Steeds, Appl. Phys. Lett., 69, 770, 1996. 
[7] X. H. Wu, C. R. Elsass, A. Abare, M. Mack, S. Keller, P. M. Petroff, S. P. DenBaars, J. S. Speck, S. J. Rosner, Appl. Phys. Lett., 72, 692, 1998. [8] S. Srinivasan, L. Geng, R. Liu, F. A. Ponce, Y. Narukawa, S. Tanaka, Appl. Phys. Lett., 83, 5187, 2003.

[9] M. Shiojiri, C. C. Chuo, J. T. Hsu, J. R. Yang and H. Saijo, J. Appl. Phys., 99, 073505, 2006. [10] A. H. Cottrell, Proc. Phys. Soc., 62, 49, 1949.

[11] J. Elsner, R. Jones, P. K. Sitch, V. D. Porezag, M. Elstner, T. Frauenheim, M. I. Heggie, S. Öberg, and P. R. Briddon, Phys. Rev. Lett., 79, 3672, 1997.

[12] C. J. Fall, R. Jones, P. R. Briddon, A. T. Blumenau, T. Frauenheim, and M. I. Heggie, Phys. Rev. B, 65, 245304, 2002.

[13] L. Lymperakis, J. Neugebauer, M. Albrecht, T. Remmele, and H. P. Strunk, Phys. Rev. Lett., 93, 196401, 2004.

[14] S. M. Lee, M. A. Belkhir, X.Y. Zhu, Y. H. Lee, Y. G. Hwang, and T. Frauenheim, Phys. Rev. B, 61, 16033, 2000.

[15] S. J. Henleya and D. Cherns, J. Appl. Phys., 93, 3934, 2003.

[16] J. W. P. Hsu, M. J. Manfra, R. J. Molnar, B. Heying, J. S. Speck, Appl. Phys. Lett., 81, 79, 2002.

[17] J. Chen, P. Ruterana, G. Nouet, Mater. Sci. Engg. B, 82, 117, 2001.

[18] A. Béré, A. Serra, Phys. Rev. B, 65, 205323, 2002.

[19] J. Kioseoglou, Ph. Komninou, Th. Karakostas, Phys. Stat. Sol. (a), 206, 1931, 2009.

[20] H. P. Lei, R. Ruterana, G. Nouet, X. Y. Jiang, J. Chen, Appl. Phys. Lett., 90, 111901, 2007.

[21] J. Kioseoglou, Ph. Komninou, Th. Karakostas, Phys. Stat. Sol. A, 206, 1931, 2009.

[22] Joseph Kioseoglou, Phys. Stat. Sol. A, 210, 204, 2013.

[23] P. B. Hirsch, J. G. Lozano, S. Rhode, M. K. Horton, M. A. Moram, S. Zhang, M. J. Kappers, C. J. Humphreys, A. Yasuhara, E. Okunishi, and P. D. Nellist, Philos. Mag., 93, 3925, 2013.

[24] S. K. Rhode, M. K. Horton, M. J. Kappers, S. Zhang, C. J. Humphreys, R.O. Dusane, S.-L. Sahonta, M. A. Moram, Phys. Rev. Lett., 111, 025502, 2013.

[25] F. C.-P. Massabuau, L. Trinh-Xuan, D. Lodié, E. J. Thrush, D. Zhu, F. Oehler, T. Zhu, M. J. Kappers, C. J. Humphreys, R. A. Oliver, J. Appl. Phys, 113, 073505, 2013.

[26] S. L. Rhode, W. Y. Fu, M. A. Moram, F. C.-P. Massabuau, M. J. Kappers, C. McAleese, F. Oehler, C. J. Humphreys, R. O. Dusane, and S.-L. Sahonta, J. Appl. Phys., 116, 103513, 2014. 
[27] E. Taylor, F. Fang, F. Oehler, P. R. Edwards, M. J. Kappers, K. Lorenz, E. Alves, C. McAleese, C. J. Humphreys, and R. W. Martin, Semicond. Sci. Technol. 28, 065011, 2013.

[28] M. J. Kappers, R. Datta, R.A. Oliver, F. D. G. Rayment, M. E. Vickers, C. J. Humphreys, J. Cryst. Growth, 300, 70, 2007.

[29] A. Mouti, J.-L. Rouvière, M. Cantoni, J.-F. Carlin, E. Feltin, N. Grandjean, P. Stadelmann, Phys. Rev. B, 83, 195309, 2011.

[30] S. Plimpton, J. Comput. Phys., 117, 1, 1995.

[31] I. Belabbas, A. Béré, J. Chen, S. Petit, M. Akli Belkhir, P. Ruterana, and G. Nouet, Phys. Rev. B, 75, 115201, 2007.

[32] A. Béré, J. Chen, P. Ruterana, A. Serra, G. Nouet, Comp. Mat. Sci., 24, 144, 2002.

[33] M. K. Horton, S. L. Rhode, S.-L. Sahonta, M. J. Kappers, S. Haigh, T. J. Pennycook, C. McAleese, C. J. Humphreys, R. O. Dusane, and M. A. Moram, Nano Letters, 15, 923, 2015

[34] M. K. Horton, S. K. Rhode, M. A. Moram, J. Appl. Phys., 116, 063710, 2014.

[35] J. G. Lozano, H. Yang, M. P. Guerrero-Lebrero, A. J. D’Alfonso, A. Yasuhara, E. Okunishi, S. Zhang, C. J. Humphreys, L. J. Allen, P. L. Galindo, P. B. Hirsch, P. D. Nellist, Phys. Rev. Lett., 113, 135503, 2014.

[36] R. D. Shannon, Acta Cryst., A32, 751, 1976.

[37] F. Fiore and C.L. Bauer, Prog. Mater. Sci. 13, 85, 1968.

[38] H. Lei, J. Chen, P. Ruterana, Appl. Phys. Lett., 96, 161901, 2010.

[39] H. Lei, J. Chen, P. Ruterana, J. Appl. Phys., 108, 103503, 2010.

[40] T. Sugahara, M. Hao, T. Wang, D. Nakagawa, Y. Naoi, K. Nishino, S. Sakai, Jpn. J. Appl. Phys. 37, L1195, 1998.

[41] H. Sato, T. Sugahara, Y. Naoi, S. Sakai, Jpn. J. Appl. Phys., 37, 2013, 1998.

[42] M. Müller, G.D.W. Smith, B. Gault, C. R. M. Grovenor, Acta Materialia, 60, 4277, 2012.

[43] N. Duxbury, U. Bangert, P. Dawson, E. J. Thrush, W. Van Der Stricht, K. Jacobs, I. Moerman, Appl. Phys. Lett., 76, 1600, 2000.

[44] G. Cliff, G. W. Lorimer, J. Microscopy, 103, 203, 1975.

[45] T. L. Song, J. Appl. Phys., 98, 084906, 2005.

[46] J. E. Northrup, L. T. Romano, J. Neugebauer, Appl. Phys. Lett., 74, 2319, 1999.

[47] A. I. Duff, L. Lymperakis, J. Neugebauer, Phys. Rev. B, 89, 085307, 2014. 
[48] T. M. Smeeton, M. J. Kappers, J. S. Barnard, M. E. Vickers, C. J. Humphreys, Appl. Phys. Lett., 83, 5419, 2003.

[49] Supplementary data for EPSRC.

\begin{tabular}{|c|c|c|c|c|}
\hline & $\begin{array}{c}5 / 7 \text {-atom ring } a \text { - } \\
\text { cores } \%\end{array}$ & $\begin{array}{c}\text { Dissociated } \\
(a+c) \text {-cores } \%\end{array}$ & $\begin{array}{c}\text { Undissociated } \\
(a+c) \text {-cores }\end{array}$ & $\begin{array}{c}\text { Dissociation } \\
\text { length }(\mathrm{nm})\end{array}$ \\
\hline Sample A & 100 & $54 \pm 5$ & $46 \pm 5$ & $1.11 \pm 0.04$ \\
\hline Sample B & 100 & $57 \pm 6$ & $43 \pm 6$ & $0.95 \pm 0.03$ \\
\hline Sample C & 100 & $50 \pm 5$ & $50 \pm 5$ & $1.46 \pm 0.01$ \\
\hline Sample D & 100 & $50 \pm 5$ & $50 \pm 5$ & $1.85 \pm 0.06$ \\
\hline
\end{tabular}

Table 1: Statistics relating to core structure types in Samples A-D obtained by STEM imaging of $>50$ dislocations for each sample. The undissociated $(a+c)$-cores in all samples include only the double 5/6-atom rings (Fig. 2 (a)). 


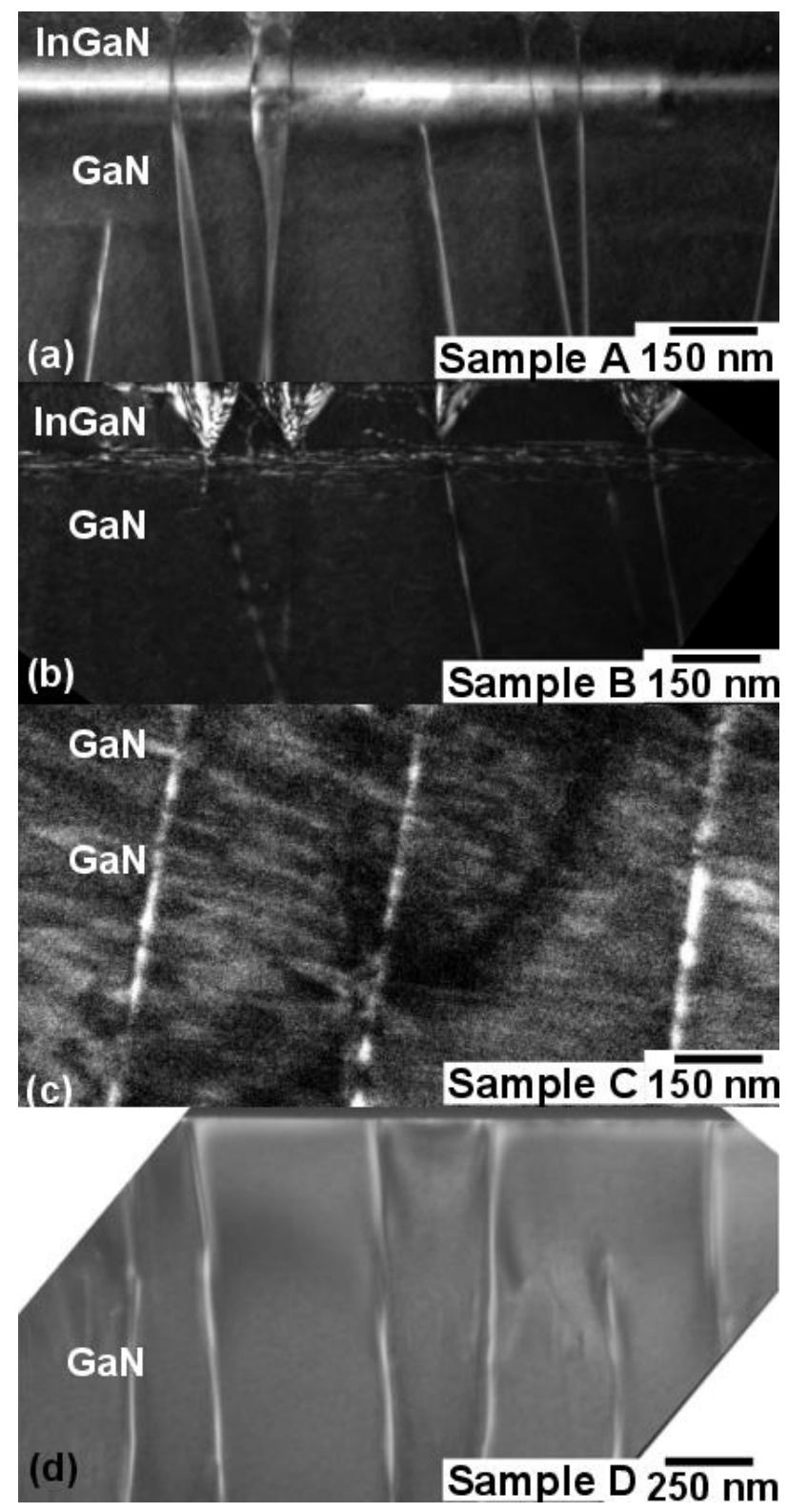

Figure 1: Cross-sectional WBDF TEM micrographs acquired under $\mathbf{g}(3 \mathbf{g})$ conditions to activate $\mathbf{g}$ $=(10 \overline{1} 0)$ for Sample (a) A (b) B (c) C and (d) D. 


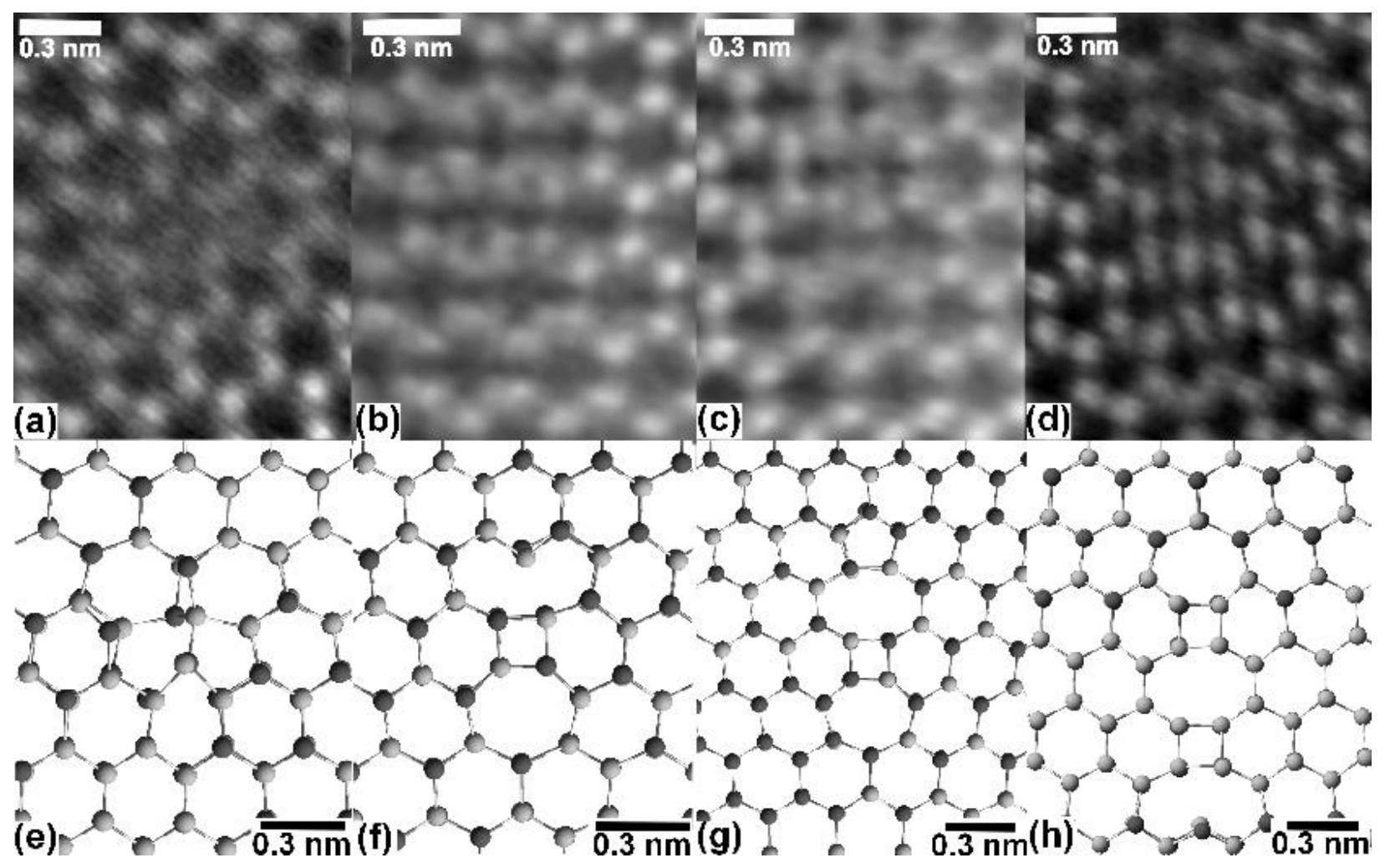

Figure 2: Plan-view STEM-HAADF images of $(a+c)$-type dislocation core structures found in an $\mathrm{In}_{0.057} \mathrm{Ga}_{0.943} \mathrm{~N}$ epilayer (Sample A) showing (a) undissociated double 5/6- and (b) 7/4/9-atom cores and dissociated (c) 7/4/8/5- and (d) 7/4/8/4/9-atom cores, where (e), (f), (g) and (h) are obtained from molecular dynamics simulations. White spheres represent Ga atoms and dark spheres represent $\mathrm{N}$ atoms. 


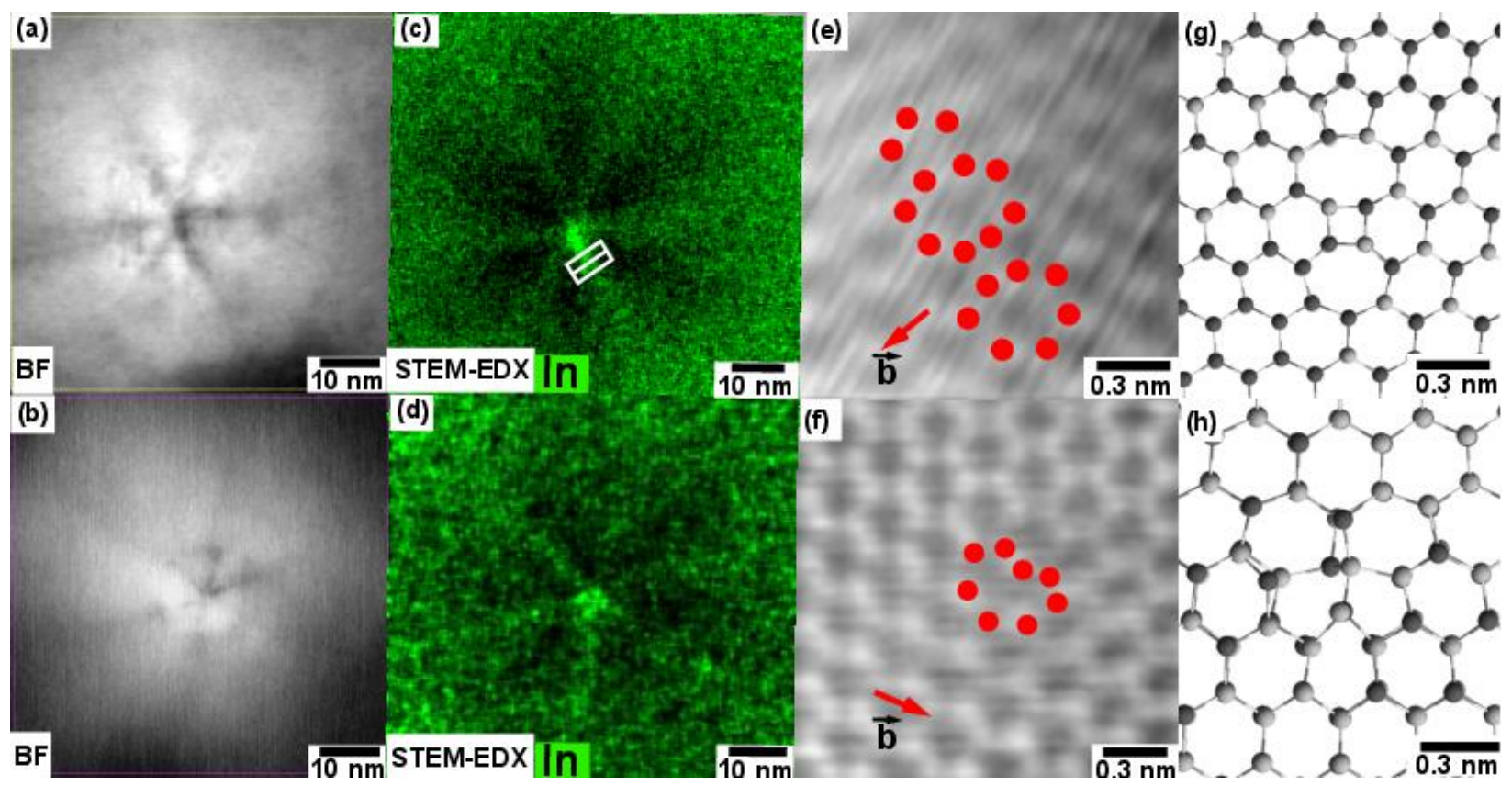

Figure 3: $\mathrm{BF}$ images obtained at $(a+c)$-type dislocations which terminate as $\mathrm{V}$-defects at the surface of (a) an $\mathrm{In}_{0.057} \mathrm{Ga}_{0.943} \mathrm{~N}$ epilayer (Sample A) and (b) an $\mathrm{In}_{0.20} \mathrm{Ga}_{0.80} \mathrm{~N}$ epilayer (Sample B) with their corresponding STEM-EDXS elemental maps of In, as shown in (c) and (d) respectively. The alternating $\mathrm{Ga}$ and $\mathrm{N}$ atomic columns comprising the TD core structures in (e) and (f) are labelled with red dots to aid the eye. The core structures shown in (g) and (h) obtained through atomistic modelling are believed to correspond to the core structures reported in (e) and (f) respectively. The In content in the regions marked in (c) was quantified by Cliff-Lorimer analysis.
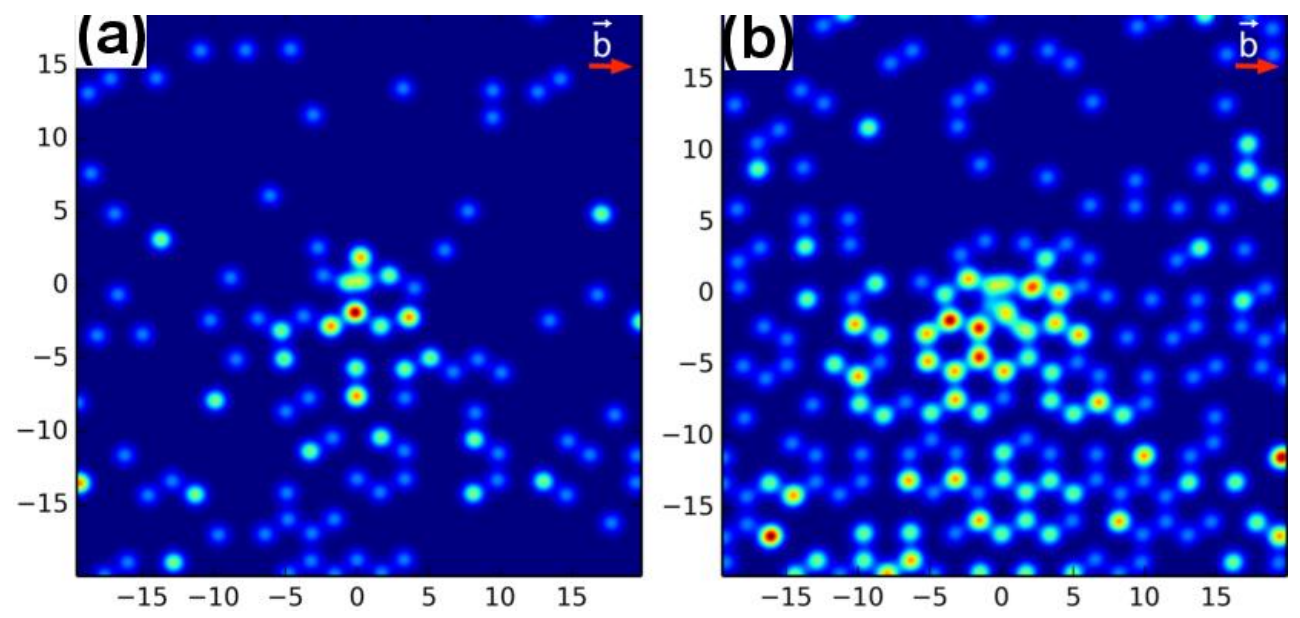

Figure 4: Monte Carlo simulations show the likelihood of finding In atoms at each atomic location for a typical equilibrium configurations of an $(a+c)$-type dislocation core in $\operatorname{In}_{x} \mathrm{Ga}_{1-x} \mathrm{~N}$ 
for (a) $x=0.0625$ and (b) $x=0.1875$ (using a 2D kernel density estimator). All figures are planview along [0001], with the axes in units of Angstroms. The color scale varies from red (high concentration) to dark blue (low concentration, no In atoms), with dislocation cores at the origins of both plots.

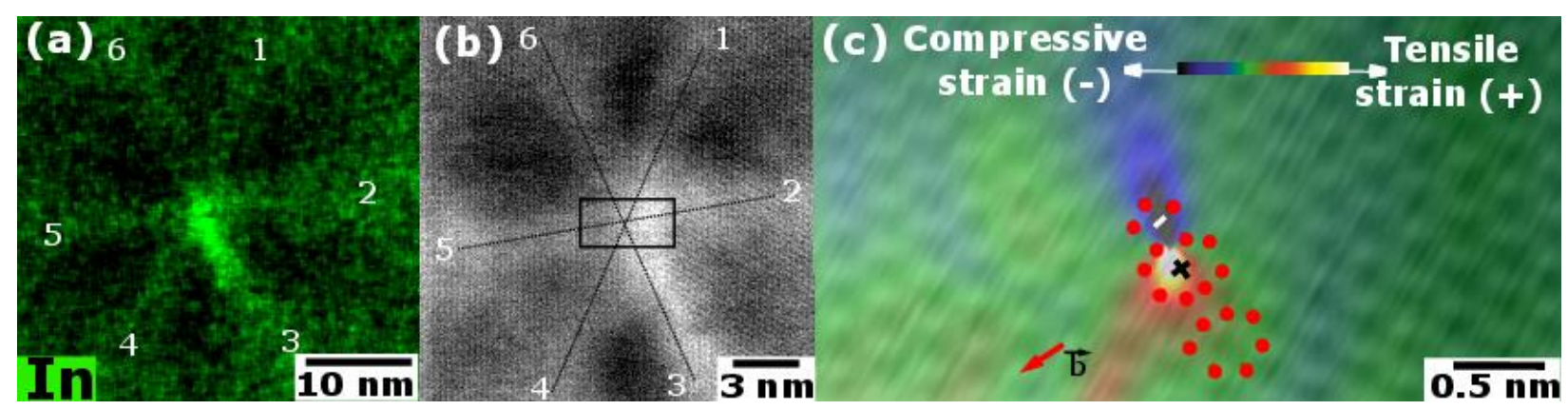

Figure 5: (a) STEM-EDXS In elemental map showing In segregation along vertex 3 of an $(a+c)$ type dislocation in $\mathrm{In}_{0.057} \mathrm{Ga}_{0.943} \mathrm{~N}$ epilayer (Sample A), (b) shows the corresponding plan-view high-resolution STEM-HAADF image of the V-defect shown in (a) and (c) shows the calculated $x$-x GPA strain-map $\left(\varepsilon_{x x}\right)$ of the boxed region in (b), superimposed on its corresponding atomicresolution STEM-HAADF image. Atomic columns at the TD core are marked with red dots in (c) and vertices between the V-defect facets are labelled numerically in both (a) and (b).

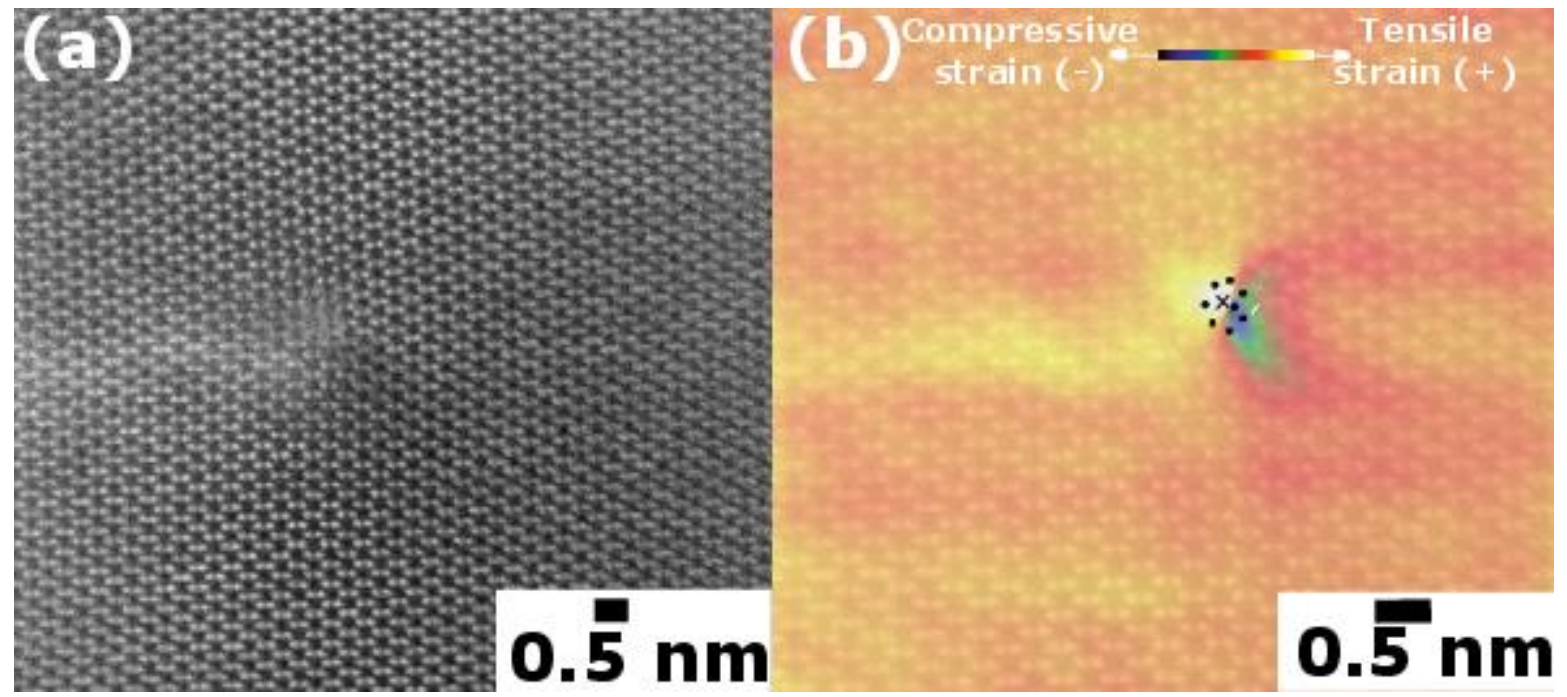

Figure 6: (a) Plan-view STEM-HAADF image of an $(a+c)$-type TD in Sample $\mathrm{C}$ and its corresponding (b) strain-field map $\left(\varepsilon_{\mathrm{xx}}\right)$ superimposed on its STEM-HAADF image, where the double 5/6-atom core structure and the tensile and compressive regions near the $(a+c)$-type TD are labelled. 

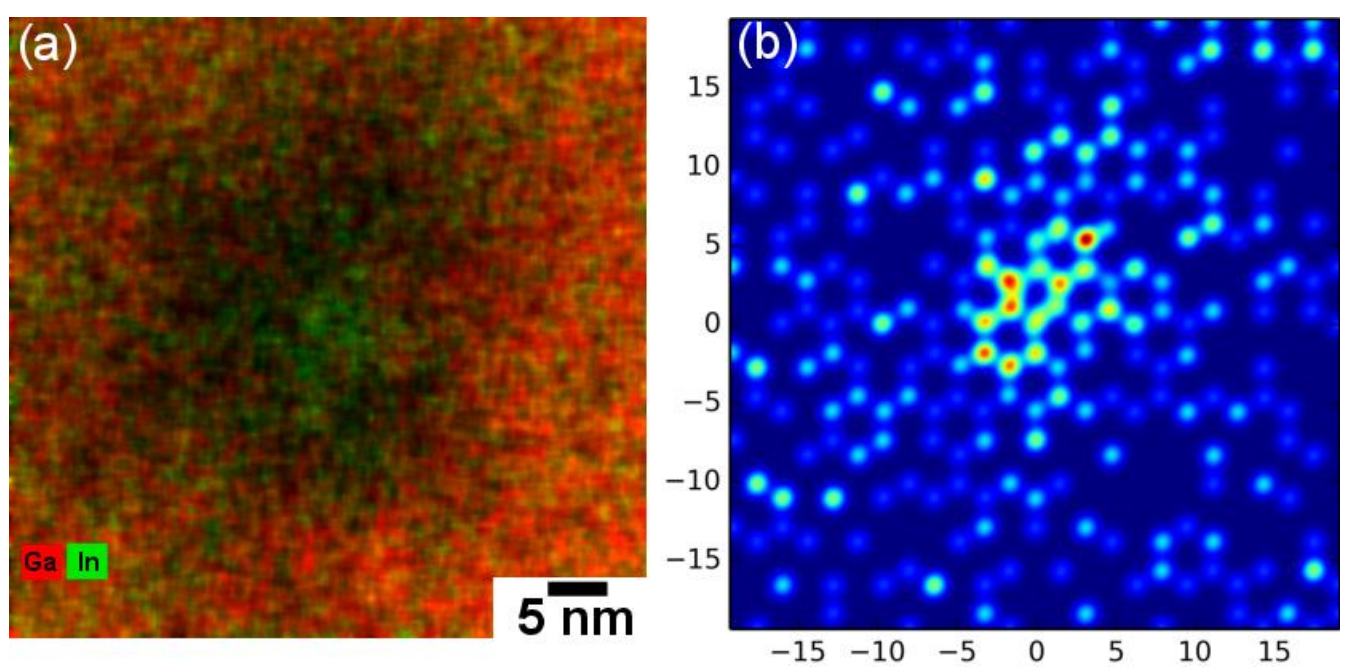

Figure 7: (a) STEM-EDXS elemental maps of Ga and In obtained at a $c$-type TD which terminates as a V-defect at the surface of an $\operatorname{In}_{0.057} \mathrm{Ga}_{0.943} \mathrm{~N}$ epilayer (Sample A), and (b) shows the corresponding Monte Carlo simulation shows the probability of finding In atoms at each atomic location for a typical equilibrium configurations of a $c$-type dislocation core in $\operatorname{In}_{x} \mathrm{Ga}_{1-x} \mathrm{~N}$ with $x=0.0625$ (using kernel density estimators). All figures are plan-view along [0001], with the axes in units of Angstroms in (c). The color scale in (b) is from red (high concentration) to dark blue (low concentration). 